Research Paper

\title{
Efficacy of the Additional Neoadjuvant Chemotherapy to Concurrent Chemoradiotherapy for Patients with Locoregionally Advanced Nasopharyngeal Carcinoma: a Bayesian Network Meta-analysis of Randomized Controlled Trials
}

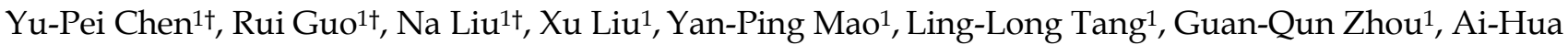
Lin $^{2}$, Ying Sun 1 , Jun Ma ${ }^{1 凶}$

1. Sun Yat-sen University Cancer Center, State Key Laboratory of Oncology in South China, Collaborative Innovation Center of Cancer Medicine, Guangzhou, People's Republic of China

2. Department of Medical Statistics and Epidemiology, School of Public Health, Sun Yat-sen University, Guangzhou, People's Republic of China

$\dagger$ These authors contributed equally to this work.

$\triangle$ Corresponding author: Jun Ma, State Key Laboratory of Oncology in South China, Department of Radiation Oncology, Sun Yat-sen University Cancer Center, 651 Dongfeng Road East, Guangzhou 510060, People's Republic of China. Tel.:+86-20-87343469; Fax:+86-20-87343295; E-mail: majun2@mail.sysu.edu.cn

(c) 2015 Ivyspring International Publisher. Reproduction is permitted for personal, noncommercial use, provided that the article is in whole, unmodified, and properly cited. See http://ivyspring.com/terms for terms and conditions.

Received: 2015.02.07; Accepted: 2015.05.05; Published: 2015.07.17

\begin{abstract}
Background: Due to the lack of studies, it remains unclear whether the additional neoadjuvant chemotherapy (NACT) to concurrent chemoradiotherapy (CCRT) is superior to CCRT alone for locoregionally advanced nasopharyngeal carcinoma (NPC). The main objective of this Bayesian network meta-analysis was to determine the efficacy of NACT+CCRT as compared with CCRT alone.

Methods: We comprehensively searched databases and extracted data from randomized controlled trials involving NPC patients who received NACT+CCRT, CCRT, NACT+radiotherapy $(R T)$, or RT. Overall survival (OS) with hazard ratio (HR), and locoregional recurrence rate (LRR) and distant metastasis rate (DMR) with relative risks (RRs), were concerned.

Results: Nine trials involving 1988 patients were analyzed. In the network meta-analysis, there was significant benefit of NACT+CCRT over CCRT for DMR ( $R R=0.54,95 \%$ credible interval $[\mathrm{Crl}]=0.27-0.94)$. However, NACT+CCRT had a tendency to worsen locoregional control significantly as compared with CCRT ( $R R=1.71,95 \% \mathrm{Crl}=0.94-2.84)$, and no significant improvement in OS was found $(\mathrm{HR}=0.73,95 \% \mathrm{Crl}=0.40-1.23)$.

Conclusions: NACT+CCRT is associated with reduced distant failure as compared with CCRT alone, and whether the additional NACT can improve survival for locoregionally advanced NPC should be further explored. Optimizing regimens and identifying patients at high risk of metastasis may enhance the efficacy of NACT+CCRT.
\end{abstract}

Key words: concurrent chemoradiotherapy, induction chemotherapy, meta-analysis, nasopharyngeal neoplasms, radiotherapy.

\section{Introduction}

Nasopharyngeal carcinoma (NPC) is a squamous-cell carcinoma with uneven worldwide distribution and high prevalence in Southeast Asia and
North Africa [1]. Radiotherapy (RT) is the mainstay treatment modality for NPC. With the advent of intensity modulated radiation therapy (IMRT), the lo- 
coregional control has been improved significantly, but overall survival (OS) and especially distant failure control are still limited by RT alone [2,3].

Due to the apparent chemosensitivity of NPC, plentiful studies were carried out to evaluate the use of chemotherapy (neoadjuvant, concurrent and adjuvant chemotherapy) in combination with $\mathrm{RT}$ for the management of locoregionally advanced NPC. Clinical trials and systematic reviews have demonstrated concurrent chemoradiotherapy (CCRT) to be the most efficacious, and the current standard treatment for locoregionally advanced NPC is CCRT with or without adjuvant chemotherapy [4-6]. However, the role of neoadjuvant chemotherapy (NACT) still remains controversial. Randomized controlled trials (RCTs) of NACT followed by RT have resulted in favorable response rates and improvement in disease-free survival, but not OS [7-10]. A recent meta-analysis indicated that NACT could effectively enhance OS and reduce distant metastasis rate (DMR) [11]. Taking these results into account, a sequential schedule of NACT followed by CCRT is a reasonable strategy for improving prognosis of locoregionally advanced NPC with the wide adoption of IMRT.

So far, only two trials comparing NACT followed by CCRT with CCRT has been published. The trial by Hui et al. [12] reported an improvement of OS by NACT+CCRT, but the trial by Fountzilas et al. [13] failed to observe any significant improvement in survival. Given the lack of studies, the efficacy of the addition of NACT to CCRT remains unclear. Therefore, it is important to perform this network meta-analysis, which provides useful information on comparisons of the four regimens (NACT+CCRT, CCRT, NACT+RT, and RT) by integrating direct and indirect methods, to demonstrate the additional value of NACT, and to verify its efficacy for locoregionally advanced NPC.

\section{Materials and methods}

\section{Study criteria}

This meta-analysis was conducted according to the Preferred Reporting Items for Systematic Reviews and Meta-Analyses (PRISMA) guidelines [14]. The inclusion criteria for eligible studies were: (1) patients with histologically proven NPC (WHO type 1 to 3 ), without distant metastasis at presentation; (2) computed tomography and/or magnetic resonance imaging scan being used as the main evaluation method; (3) patients being treated with definitive radiation, with adequate doses of radiotherapy (equivalent to at least $66 \mathrm{~Gy}$, with conventional fraction to the primary lesion) in both arms; (4) RCTs with unpredictable treatment assignment; (5) the majority of the enrolled patients had locoregionally advanced NPC (stage III or IV according to the staging system used in the trial); (6) patients receiving NACT+CCRT, CCRT or $\mathrm{NACT}+\mathrm{RT}$ in experimental arm compared with patients receiving CCRT, NACT+RT or RT in control arm; (7) RT being begun 3 weeks after the completion of NACT for better tolerance of chemoradiotherapy in patients receiving NACT+CCRT.

\section{Literature search strategy}

We aimed to include all the relevant published trials. The following electronic databases were searched to identify potentially eligible studies up to November, 2014: PubMed, Embase, and the Central Registry of Controlled Trials of the Cochrane Library. Moreover, it was supplemented by manual search of reference lists of primary studies, published reports, relevant books, and review articles. Searching headlines included nasopharyngeal carcinoma or cancer or neoplasm, neoadjuvant or induction chemotherapy, concurrent chemoradiotherapy and radiotherapy. The search was limited to RCTs but not English language.

\section{Quality control}

To assess the quality of RCTs, the randomization process, estimation of sample size, allocation concealment, the analysis methods, loss to follow-up, and dropout were examined. Jadad/Oxford quality scoring system was used for the quantitative analysis of trials [15]. Any discrepancies were resolved by consensus.

\section{Method of data retrieves}

Two independent investigators (Y.P. Chen and R. Guo) reviewed the publications and extracted the data. Data on study design, year, inclusion criteria, sample size per group, randomization scheme, staging information, follow-up duration, treatment protocol, end points, and failure patterns were abstracted independently. Any discrepancies were discussed by the two investigators to reach consensus.

\section{Statistical analysis}

The primary endpoint of this network meta-analysis was OS, defined as the time from random assignment to death. Secondary end points were locoregional recurrence rate (LRR) and DMR. Results regarding OS was expressed as hazard ratio (HR), which was the only summary statistic allowed for both censoring and time to an event. If HR and its variance were available directly in an individual trial, then these values were used. If not, extraction of summary statistics in an individual trial was performed according to methods detailed by Parmar et al. [16], and the observed minus expected number of deaths (O-E) and its variance were calculated for each 
trial. For the incidence of locoregional recurrence and distant metastasis, only the absolute number of events was mentioned in most reports. Therefore, the relative risks (RR) was used as a summary statistic for LRR and DMR.

First, traditional pairwise meta-analyses were conducted by using Review Manager Version 5.0.24 (Revman; the Cochrane Collaboration; Oxford, England). The Mantel-Haenszel test was used for LRR and DMR. A two-sided $P$-value of $<0.05$ was considered significant. Heterogeneity across studies was tested by $X^{2}$ test and $I^{2}$ statistic along with a forest plot. Statistically significant heterogeneity was defined as a $X^{2} P$-value $<0.1$ or an $I^{2}$ statistic $>50 \%$ (both are two-sided).

Second, the network meta-analyses within a Bayesian framework using Markov chain Monte Carlo methods were built in WinBUGS 1.4.3 (MRC Biostatistics Unit, Cambridge, UK) [17]. We applied both the fixed and random effect models proposed by Woods and colleagues, which could preserve randomization and avoid potential selection bias, misleading results, and loss of available treatment comparisons [18]. Treatment effects were estimated by posterior means with corresponding 95\% credible intervals (CrIs), which can be interpreted similarly to conventional 95\% confidence intervals (CIs) [19]. The main difference between the fixed and random effect models is that the latter considers between-study variance, thereby producing wider CrIs, and is preferred in the presence of heterogeneity. We used Bayesian deviance information criterion (DIC) statistics to compare the two models. The DIC provides a measure of model fit that penalizes model complexity, with lower values suggesting a simpler model and differences of 2-5 considered important [20].

We used non-informative uniform and normal prior distributions to fit the model, yielding at least 50,000 iterations with a burn-in number of 10,000 iterations, and a thin interval of 50 to obtain the posterior distributions of the model parameters. We assessed convergence by using the Brooks-GelmanRubin method [21].

The probability of each treatment being the best, second best, and third best was estimated based on its posterior probabilities. We assessed the probability by counting the proportion of iterations in the Markov chain of HR or RR ranking in the treatments. The Bayesian network meta-analyses results were compared with pairwise meta-analyses results to evaluate inconsistency.

To address severe acute toxicities ( $\geq$ Grade 3 ), we compared toxicity rates between experimental and control arms during RT or CCRT following NACT with the $\chi^{2}$ test.

\section{Results}

\section{Eligible studies}

After the selection procedure (Fig. 1), a total of 9 trials were considered eligible [7-10, 12, 13, 22-26]. Table 1 lists their baseline characteristics. The study by Chan et al. was first published in 2002 [22] and updated in 2005 with the 5-year OS data [23]. The same updates were made to Zhang's trial [25, 26]. Kwong's trial is a factorial study to test the efficacy of CCRT and AC independently [24], with patients divided into four treatment groups: Group A (RT alone), Group B (CCRT), Group C (RT and AC) and Group D (CCRT and AC). In our study, we took Group A and Group B for the multiple treatment comparisons. These pooled 9 trials involved 1988 randomly assigned patients, of whom 890 received RT alone, 606 received NACT+RT, 386 received CCRT, and 106 received NACT+CCRT. The OS, LRR and DMR were available for all trials. Table 2 describes the assessment of the quality of all eligible RCTs.

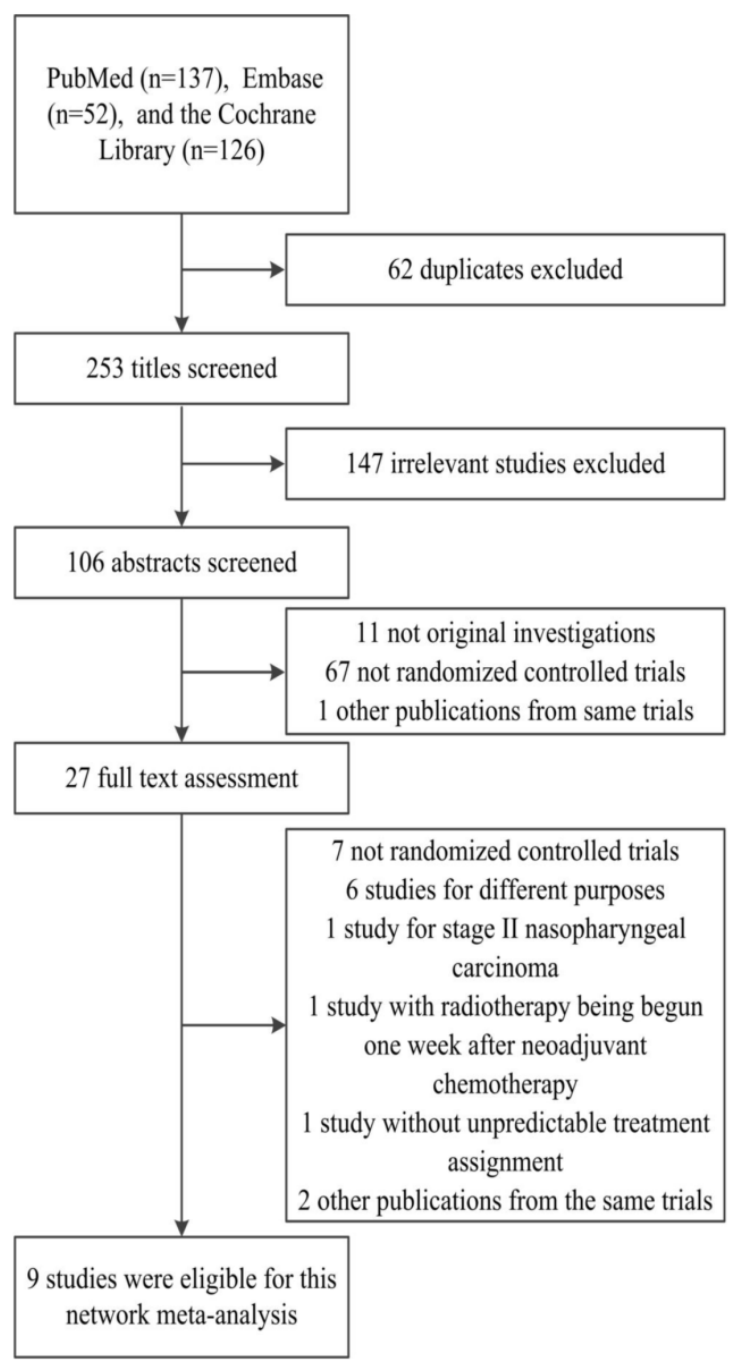

Figure 1. Flowchart of randomized controlled trial selection. 
Table 1. Summary of studies included in the network meta-analysis

\begin{tabular}{|c|c|c|c|c|c|c|c|}
\hline \multirow[t]{2}{*}{ Study } & \multirow{2}{*}{$\begin{array}{l}\text { No. of } \\
\text { patients }\end{array}$} & \multirow{2}{*}{$\begin{array}{l}\text { Inclusion } \\
\text { period }\end{array}$} & \multirow{2}{*}{$\begin{array}{l}\text { Median } \\
\text { follow-up } \\
\text { (months) }\end{array}$} & \multirow[t]{2}{*}{ Stage } & \multirow[t]{2}{*}{ Radiotherapy } & \multicolumn{2}{|l|}{ Chemotherapy } \\
\hline & & & & & & Neoadjuvant & Concurrent \\
\hline \multicolumn{8}{|l|}{ NACT+RT vs. $R T$} \\
\hline $\begin{array}{l}\text { Cvitcovics et al. [7] } \\
1996\end{array}$ & 339 & $1989-1993$ & 49 & $\begin{array}{l}\text { AJCC any } \mathrm{T}, \\
\mathrm{N} 2-3\end{array}$ & $\begin{array}{l}2.0 \mathrm{~Gy} / \mathrm{fx} / \mathrm{d}, 5 \mathrm{fx} / \mathrm{wk} \text {, to } \\
65-70 \mathrm{~Gy}\end{array}$ & $\begin{array}{l}3^{*} \text { DDP } 100 \mathrm{mg} / \mathrm{m}^{2}(\text { day } 1) \\
\text { +bleomycin } 15 \mathrm{mg} \\
\text { bolus }+12 \mathrm{mg} / \mathrm{m}^{2} / \mathrm{d} \\
\text { (days } 1-5),+ \text { epirubicin } 70 \mathrm{mg} / \mathrm{m}^{2} \\
\text { (day } 1 \text { ) }\end{array}$ & None \\
\hline $\begin{array}{l}\text { Chua et al. [8] } \\
1998\end{array}$ & 334 & 1989-1993 & 30 & $\begin{array}{l}\text { Ho's stage } \\
\text { III-IV, N } \geq 3 \mathrm{~cm}\end{array}$ & $\begin{array}{l}60-66 \mathrm{~Gy}, \text { + additional } \\
\text { boost in case of residual neck } \\
\text { node,hypofractionated } \\
\text { radiotherapy for most }\end{array}$ & $\begin{array}{l}\left.2-3^{*} \text { DDP } 60 \mathrm{mg} / \mathrm{m}^{2} \text { (day } 1\right) \\
\left.\text { +epirubicin } 110 \mathrm{mg} / \mathrm{m}^{2} \text { (day } 1\right)\end{array}$ & None \\
\hline $\begin{array}{l}\text { Ma et al. [9] } \\
2001\end{array}$ & 456 & 1993-1994 & 62 & $\begin{array}{l}\text { Chinese } 1992 \\
\text { stage III-IV }\end{array}$ & $\begin{array}{l}2.0 \mathrm{~Gy} / \mathrm{fx} / \mathrm{d}, 5 \mathrm{f} / \mathrm{wk} \text {, to } 68-72 \mathrm{~Gy} \text {, } \\
\text { +additional boost to } 80 \mathrm{~Gy} \text { if re- } \\
\text { sidual }\end{array}$ & $\begin{array}{l}\left.\text { 2-3* DDP } 100 \mathrm{mg} / \mathrm{m}^{2} \text { (day } 1\right) \\
\left.+ \text { FU } 800 \mathrm{mg} / \mathrm{m}^{2} / \mathrm{d} \text { (days } 1-5 \mathrm{civ}\right) \\
\text { + bleomycin } \\
\left.10 \mathrm{mg} / \mathrm{m}^{2} / \mathrm{d} \text { (days } 1 \text { and } 5\right)\end{array}$ & None \\
\hline $\begin{array}{l}\text { Hareyama et al. [10] } \\
2002\end{array}$ & 80 & 1991-1998 & 49 & All stages, M0 & $\begin{array}{l}2.0-2.2 \mathrm{~Gy} / \mathrm{fx} / \mathrm{d}, 5 \mathrm{fx} / \mathrm{wk} \text {, to } 66-68 \\
\text { Gy }\end{array}$ & $\begin{array}{l}2^{*} \mathrm{DDP} 80 \mathrm{mg} / \mathrm{m}^{2}(\text { day } 1),+\mathrm{FU} \\
800 \mathrm{mg} / \mathrm{m}^{2}(\text { days } 1-4 \text { civ })\end{array}$ & None \\
\hline \multicolumn{8}{|l|}{ CCRT vs. RT } \\
\hline $\begin{array}{l}\text { Chan et al. [22,23] } \\
\text { 2002,2005 }\end{array}$ & 350 & 1994-1997 & 66 & $\begin{array}{l}\text { AJCC II- IV, } \\
\text { any T, any N, } \\
\text { M0 }\end{array}$ & $\begin{array}{l}66 \mathrm{~Gy},+ \text { additional boost } \\
\text { in case of parapharyngeal } \\
\text { extension, residual neck } \\
\text { nodes, and/or residual } \\
\text { nasopharyngeal } \\
\text { disease (brachytherapy) }\end{array}$ & None & $\begin{array}{l}8^{*} \text { DDP } 40 \\
\mathrm{mg} / \mathrm{m}^{2} \\
(\text { day } 1) \text { weekly }\end{array}$ \\
\hline $\begin{array}{l}\text { Kwong et al. [24] } \\
2004^{\mathrm{a}}\end{array}$ & 108 & $1995-2001$ & 37 & $\begin{array}{l}\text { AJCC II-IV, } \\
\text { any T, any N }\end{array}$ & $\begin{array}{l}2.5 \mathrm{~Gy} / \mathrm{fx} / \mathrm{d}, 5 \mathrm{fx} / \mathrm{wk} \text {, } \\
\text { to } 66-68 \mathrm{~Gy},+10 \mathrm{~Gy} \text { boost dose for } \\
\text { pharyngeal extension and residual } \\
\text { nodes }\end{array}$ & None & $\begin{array}{l}\text { UFT } 600 \mathrm{mg} / \mathrm{d} \text {, } \\
7 \mathrm{~d} / \mathrm{wk}\end{array}$ \\
\hline $\begin{array}{l}\text { Zhang et al. }[25,26] \\
2005,2013\end{array}$ & 115 & $2001-2003$ & 114 & $\begin{array}{l}\text { AJCC III-IV, } \\
\text { any } \\
\text { T, N2 or } \\
\text { N3, M0 }\end{array}$ & $\begin{array}{l}70-74 \mathrm{~Gy}(2 \mathrm{~Gy} / \mathrm{fx} / \mathrm{d}, 5 \mathrm{fx} / \mathrm{wk}) \\
\text { +additional boost in case } \\
\text { of parapharyngeal } \\
\text { extension, residual neck } \\
\text { nodes and/or residual } \\
\text { nasopharyngeal disease }\end{array}$ & None & $\begin{array}{l}6^{*} \text { Oxaliplatin } 70 \\
\mathrm{mg} / \mathrm{m}^{2} \text { weekly }\end{array}$ \\
\hline \multicolumn{8}{|l|}{$\begin{array}{l}\text { NACT+CCRT vs. } \\
\text { CCRT }\end{array}$} \\
\hline $\begin{array}{l}\text { Hui et al. [12] } \\
2009\end{array}$ & 65 & $2002-2004$ & 51.6 & AJCC III-IVB & $\begin{array}{l}2 \mathrm{~Gy} / \mathrm{fx} / \mathrm{d}, 5 \mathrm{fx} / \mathrm{wk} \text {, to } 66 \mathrm{~Gy} \\
\text { residual boost of } 7.5 \mathrm{~Gy} \text {, and par- } \\
\text { apharyngeal boost of } 20 \mathrm{~Gy} b\end{array}$ & $\begin{array}{l}2^{*} \text { q3wk DDP } 75 \mathrm{mg} / \mathrm{m}^{2} \\
\text { (day } 1),+ \text { docetaxel } 75 \\
\left.\mathrm{mg} / \mathrm{m}^{2} \text { (day } 1\right)\end{array}$ & $\begin{array}{l}8^{*} \text { DDP } 40 \\
\mathrm{mg} / \mathrm{m}^{2} \text { weekly }\end{array}$ \\
\hline $\begin{array}{l}\text { Fountzilas et al. [13] } \\
2012\end{array}$ & 141 & 2003-2008 & 55 & AJCC IIB-IVB & $2.0 \mathrm{~Gy} / \mathrm{fx} / \mathrm{d}, 5 \mathrm{fx} / \mathrm{wk}$, to $66-70 \mathrm{~Gy} b$ & $\begin{array}{l}3^{*} \text { q3wk DDP } 75 \mathrm{mg} / \mathrm{m}^{2}(\text { day } 2) \\
+ \text { epirubicin } \\
75 \mathrm{mg} / \mathrm{m}^{2},+ \text { paclitaxel } 175 \\
\mathrm{mg} / \mathrm{m}^{2}(\text { day } 1)\end{array}$ & $\begin{array}{l}\text { DDP } 40 \mathrm{mg} / \mathrm{m}^{2} \\
\text { weekly }\end{array}$ \\
\hline
\end{tabular}

Table 2. Assessing quality of all the 9 included studies

\begin{tabular}{|c|c|c|c|c|c|c|c|}
\hline Study & $\begin{array}{l}\text { Randomization } \\
\text { process }\end{array}$ & $\begin{array}{l}\text { Estimation } \\
\text { of sample size }\end{array}$ & $\begin{array}{l}\text { Allocation con- } \\
\text { cealment }\end{array}$ & $\begin{array}{l}\text { Intention to } \\
\text { treat analysis }\end{array}$ & $\begin{array}{l}\text { Loss to } \\
\text { follow-up }\end{array}$ & Dropout & $\begin{array}{l}\text { Jadad } \\
\text { scores }\end{array}$ \\
\hline \multicolumn{8}{|l|}{ NACT+RT vs. $R T$} \\
\hline Cvitcovics et al. [7] 1996 & Yes & Yes & No & Yes & Yes & Yes & 3 \\
\hline Chua et al. [8] 1998 & Yes & Yes & No & Yes & No & Yes & 3 \\
\hline Ma et al. [9] 2001 & No & Yes & No & Yes & Yes & Yes & 2 \\
\hline Hareyama et al. [10] 2002 & Yes & No & No & Yes & Yes & Yes & 3 \\
\hline \multicolumn{8}{|l|}{ CCRT vs. RT } \\
\hline Chan et al. $[22,23] 2002,2005$ & Yes & Yes & No & Yes & No & Yes & 3 \\
\hline Kwong et al. [24] 2004 & No & No & No & Yes & Yes & Yes & 2 \\
\hline Zhang et al. [25,26] 2005,2013 & No & Yes & No & No & No & Yes & 2 \\
\hline \multicolumn{8}{|l|}{ NACT+CCRT vs. CCRT } \\
\hline Hui et al. [12] 2009 & Yes & Yes & No & Yes & No & Yes & 3 \\
\hline Fountzilas et al. [13]2012 & Yes & Yes & No & Yes & No & Yes & 3 \\
\hline
\end{tabular}

NACT: neoadjuvant chemotherapy; CCRT: concurrent chemoradiotherapy; RT: radiotherapy. 


\section{Direct meta-analysis}

Figure 2 presents all direct meta-analyses. Compared with RT alone, significant benefits in favor of CCRT were found for OS $(P=0.007, \mathrm{HR}=0.68$, $95 \% \mathrm{CI}=0.52-0.90)$; there was no significant difference between NACT+RT and RT, and NACT+CCRT and CCRT (Fig. 2A). NACT+RT was associated with lower locoregional recurrence risk as compared with RT alone $(P=0.005, \mathrm{RR}=0.75,95 \% \mathrm{CI}=0.61-0.92)$; there was no significant difference between CCRT and RT, and NACT+CCRT had a tendency to show significantly unfavorable results as compared with CCRT ( $P$ $=0.07, \mathrm{RR}=1.65,95 \% \mathrm{CI}=0.95-2.86$ ) (Fig 2B). There was significantly reduced distant failure in patients who received NACT $+\mathrm{RT}(P=0.002, \mathrm{RR}=0.71,95 \% \mathrm{CI}$ $=0.57-0.88)$ and CCRT $(P=0.04, \mathrm{RR}=0.73,95 \% \mathrm{CI}=$ $0.55-0.99)$ as compared with RT alone; NACT+CCRT was found to be associated with lower distant failure risk as compared with CCRT $(P=0.03, \mathrm{RR}=0.51$, $95 \% \mathrm{CI}=0.28-0.95$ ) (Fig. 2C).

\section{Network meta-analysis of efficacy}

We established a network to compare NACT+CCRT, CCRT, NACT+RT and RT alone (Fig. 3). Figure 4 summarizes the multiple treatment comparisons results for OS, LRR, and DMR. The respective sets of HRs/RRs and corresponding 95\% CrIs from the fixed and random effects models had good consistency despite the relatively wider CrIs of the latter (Fig. 4A, 4C, 4E). Based on the DIC (Fig. 4A, 4C, $4 \mathrm{E})$, the fixed effects model fit the data better than the random one, with relatively lower DIC values for all endpoints (though the differences were all in 1.5-2.0), indicating that heterogeneity might not be obvious. Furthermore, as both models yielded consistent conclusions, we applied the fixed effects model for the rest of the study.

Good coherence between direct and indirect comparisons for all endpoints was confirmed. Except the CCRT and RT LRR, and NACT+RT and RT OS, NACT+CCRT, CCRT and NACT+RT outcomes were all significantly better than RT alone. As for NACT+CCRT and CCRT, there was no significant difference between them for OS and LRR, but NACT+CCRT was associated with significantly reduced DMR (Fig. 4A, 4C, 4E). Fig. 4B, 4D, and 4F shows the probability of each treatment being ranked the best, second best, and third best, and the cumulative probabilities for the most efficacious treatments were as follows (OS, LRR, DMR): NACT+CCRT $(90 \%$, $2 \%, 95 \%)$, CCRT $(9 \%, 16 \%, 1 \%)$, NACT + RT $(1 \%, 82 \%$, $4 \%)$, and RT $(0 \%, 0 \%, 0 \%)$.

\section{Severe acute toxicities}

Table 3 summarizs the severe acute toxicities $(\geq$
Grade3) of the studies evaluating additional NACT included in this network meta-analysis. During NACT, the most commonly recorded severe acute toxicity was nausea/vomiting (25.6\%), followed by hair loss $(17.4 \%)$ and neutropenia (17.3\%) (Table 3). During CCRT in trials evaluating additional NACT (the trial by Hui et al. [12], and the trial by Fountzilas et al. [13]), no significant differences between the treatment arms were found for severe acute toxicities except the thrombocytopenia and skin (Table 3); no toxic deaths occurred in both arms in these two trials.

\section{Discussion}

This Bayesian network meta-analysis is the first study to compare the efficacy (OS, LRR and DMR) of NACT+CCRT, CCRT, NACT+RT, and RT specifically for locoregionally advanced NPC through direct and indirect statistical comparisons. In this study, good consistency between direct and indirect comparisons was confirmed for all treatment outcomes. Though in some trials a few stage I or II patients were included $[10,22-24]$, the majority ( $>90 \%$ ) of patients were stage III or IV NPC in this study.

Compared with RT alone, CCRT had a significant treatment effect on OS and DMR, but did not improve locoregional control significantly. Currently, it is recommended by European Society for Medical Oncology (ESMO) for locoregionally advanced NPC, and the additional AC following CCRT is indicated to have an uncertain benefit and a substantial toxic effect [27]. Nevertheless, CCRT may still not be adequate for certain NPC patients, especially for those with bulky and/or extensive nodal disease being at high risk of distant metastasis [28]. A pooled data analysis of two trials noted that NACT + RT could achieve modest improvements in relapse-free survival and disease-specific survival [29]. In our study, NACT+RT was found associated with reduced LRR and DMR when compared with RT alone, with a tendency to improve OS. Given the high response rate of neck node disease to NACT obtained before RT, the improvement in locoregional control is not surprising [30]. The significant shrinkage of the primary tumor by NACT, which leads to an increased safety margin between the tumor volume and the radiation volume, could reduce LRR of the locoregionally advanced NPC as well [31]. The reduced DMR can be attributed not only to early eradication of micrometastases but also to enhanced locoregional control [29]. However, the improvement in control of locoregional and distant failures does not lead to apparent gains in OS, which may be explained by the high salvage rate. As the main advantage of NACT is to eradicate distant micrometastases and decrease tumor volume before radiation, the addition of NACT to CCRT may be a reasonable approach to improve prognosis. 
A

Experimental Control

Hazard Ratio Study or Subgrou

Chua 1998

Cvitcovics 1996

Hareyama 2002
Ma 2001

Ma 2001

Events Total

Control

Hazard Ratio
O-E Variance Weight Expl(O-E)/Vl. Fixed, 95\% Cl

$0.88[0.56,1.37]$

$0.93[0.67,1.28]$

$0.87[0.43,1.77]$

Subtotal $(95 \% \mathrm{CI})$

$\begin{array}{lr}36 & 16 \\ 72 & 17 \\ 14 & 4 \\ 78 & 228\end{array}$

Heterogeneity: $\mathrm{Chi}^{2}=0.54, \mathrm{df}=3(\mathrm{P}=0.91) ; \mathrm{I}^{2}=0$

Test for overall effect: $Z=1.63(P=0.10)$

CCRT vs. RT

Chan 2002,2005

Kwong 2004

Zhang 2005,2013

$\begin{array}{lcc}\text { Total events } & 75 & 105 \\ \text { Heterogeneity: } \mathrm{Chi}^{2}=1.34, \mathrm{df}=2(P=0.51) & \mathrm{I}^{\mathrm{z}}=0 \text { 0\% }\end{array}$

Test for overall effect $Z=2.67(P=0.007)$

NACT+CCRT vs. CCRT

$\begin{array}{lrrrrrrr}\text { Fountzilas 2012 } & 25 & 72 & 23 & 69 & 0.4 & 8.22 & 72.8 \% \\ \text { Hui 2009 } & 4 & 34 & 13 & 31 & -4.38 & 3.07 & 27.2 \% \\ \text { Subtotal (95\% Cl) } & & \mathbf{1 0 6} & & \mathbf{1 0 0} & & & \mathbf{1 0 0 . 0 \%} \\ \text { Total events } & 29 & & 36 & & & & \end{array}$

Subtotal (95\%

$\begin{array}{lllll}41 & 167 & -2.49 & 19.17 & 17.9 \% \\ 74 & 168 & -2.83 & 36.46 & 34.0 \%\end{array}$

$\begin{array}{lrrrr}96 & 228 & -10.47 & 43.87 & 40.9 \%\end{array}$

$0.79[0.59,1.06]$

Heterogeneity. $\mathrm{Chi}^{2}=4.87, \mathrm{df}=1(\mathrm{P}=0.03) ; \mathrm{I}^{2}=79 \%$

Test for overall effect: $Z=1.18(P=0.24)$

B

Experimental

Control

$31.98 \quad 64.0 \%$

$5.48 \quad 11.0 \%$

$12.49 \quad 25.0 \%$
$100.0 \%$

$$
\begin{gathered}
0.71[0.50,1.00] \\
0.95[0.41,2.20] \\
0.54[0.31,0.94] \\
0.68[0.52,0.90]
\end{gathered}
$$

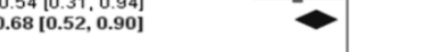

Expl(O-E) $/$ V] Fixed. 95\% C

Studv or Subgroup Events Total Events Total Weight M-H. Random.9

NACT+RT vs. RT

Chua 1998

Cvitcovics 1996

Hareyama 2002

Ma 2001

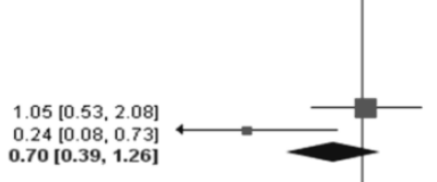

Subtotal (95\% CD)

Total events

$\begin{array}{rr}33 & 16 \\ 25 & 17 \\ 14 & 4 \\ 54 & 22 \\ & 606\end{array}$

$\begin{array}{rrrr}167 & 47 & 167 & 26.4 \% \\ 171 & 38 & 168 & 19.2 \% \\ 40 & 13 & 40 & 10.6 \%\end{array}$

$71228 \quad 10.6 \%$

$\begin{array}{rr}603 & 100.0 \%\end{array}$

Heterogeneity: Tau $^{2}=0.00 ; \mathrm{Chi}^{2}=1.86, \mathrm{df}=3(\mathrm{P}=0.60) ; \mathrm{I}^{\mathrm{z}}=0 \%$

Test for overall effect $Z=2.83(P=0.005)$

CCRT vs. RT

Chan 2002,2005

Kwong 2004

Zhang 2005,2013
Subtotal (95\% CI)

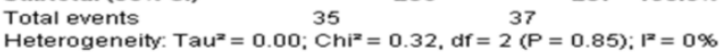

$\begin{array}{lrrrr}12 & 174 & 14 & 176 & 32.4 \%\end{array}$

$\begin{array}{lllll}10 & 53 & 9 & 55 & 26.7 \%\end{array}$

$\begin{array}{rrrr}59 & 14 & 56 & 40.9 \% \\ 286 & & 287 & 100.0 \%\end{array}$

Test for overall effect: $Z=0.28(P=0.78)$

NACT+CCRT vs. CCRT

Fountzilas 2012

Hui 2009

Total events

$\begin{array}{lllll}15 & 72 & 10 & 69 & 56.8 \%\end{array}$

$\begin{array}{rrrr}34 & 6 & 31 & 43.2 \% \\ 106 & & 100 & 100.0 \%\end{array}$ 16

Heterogeneity, $\mathrm{Tau}^{2}=0.00 ; \mathrm{Chi}^{2}=0.32, \mathrm{df}=1(\mathrm{P}=0.57) ; \mathrm{I}^{2}=0 \%$

Test for overall effect: $Z=1.78(P=0.07)$

C

Experimental Control

$0.70 .0 .48,1.04]$

$0.65[0.41,1.02]$

$0.65[0.41,1.02]$

$1.08[0.58,1.99]$

$0.76[0.56,1.03]$

Stucty or Subgroup

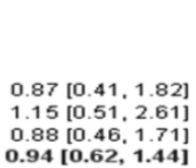

$0.88[0.46,1.71]$

$0.94[0.62,1.44]$

NACT+RT vs. RT

Chua 1998

Cvitcovics 1996

Hareyama 2002

Ma 2001

Subtotal (95\% CI)

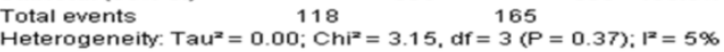

$\begin{array}{llllll}29 & 167 & 40 & 167 & 23.9 \%\end{array}$

$\begin{array}{rrrrr}29 & 167 & 40 & 167 & 23.9 \% \\ 30 & 171 & 54 & 168 & 28.2 \% \\ 11 & 40 & 16 & 40 & 11.3 \%\end{array}$

$\begin{array}{rrrrrr}11 & 40 & 16 & 40 & 11.3 \% \\ 48 & 228 & 55 & 228 & 36.6 \%\end{array}$

$\begin{array}{lllr}628 & 55 & 228 & 36.6 \% \\ 6 & & 603 & 100.0 \%\end{array}$

Test for overall effect: $Z=3.11(P=0.002)$

CCRT vs. RT

Chan 2002,2005

Kwong 2004

Zhang 2005,2013

Subtotal (95\% CI)

Total events

$\begin{array}{lllll}37 & 174 & 45 & 176 & 60.0 \%\end{array}$

$\begin{array}{rrrrr}6 & 53 & 12 & 55 & 10.7 \% \\ 15 & 59 & 22 & 56 & 29.3 \%\end{array}$

286 79

$\begin{array}{rr}56 & 29.3 \% \\ 287 & 100.0 \%\end{array}$

Test for overall effect: $Z=2.05(P=0.04)$

NACT+CCRT vs. CCRT

Fountzilas 2012

Hui 2009

Subtotal (95\% CI)

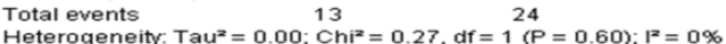

Test for overall effect $Z=2.12(P=0.03)$

Random. $95 \% \mathrm{Cl}$

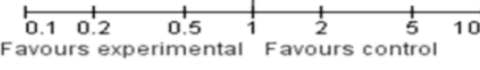

1.44 [0.69, 2.98]

$1.98[0.86,4.56]$

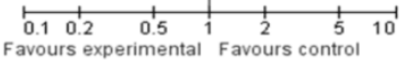

M-H. Random. 95\% CI

$0.72[0.47,1.11]$

$0.55[0.37,0.81]$

$0.69[0.37 .1 .29]$

$0.87[0.62,1.23]$

$0.71[0.57,0.88]$

$0.83[0.57,1.22]$

$0.52[0.21,1.28]$

$0.73[0.55,0.99]$

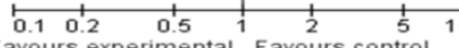

Figure 2. Direct meta-analyses of efficacy. (A) Forest plot of hazard ratio (HR) of overall survival. The estimate of the HR of each individual trial corresponds to the middle of squares and the horizontal line gives $95 \%$ confidence interval $(\mathrm{Cl})$. The closed diamond shows overall $\mathrm{HR}$ with its $95 \% \mathrm{Cl}$. $\mathrm{HR}<1$ and $95 \% \mathrm{Cl}$ excluding 1 indicate improved survival for experimental versus control arm. (B) Forest plot of relative risk (RR) of locoregional recurrence rate. (C) Forest plot of RR of distant metastasis rate. RR < 1 and $95 \%$ $\mathrm{Cl}$ excluding 1 indicate reduced locoregional recurrence rate or distant metastasis rate for experimental versus control arm. NACT: neoadjuvant chemotherapy; CCRT: concurrent chemoradiotherapy; RT: radiotherapy. 


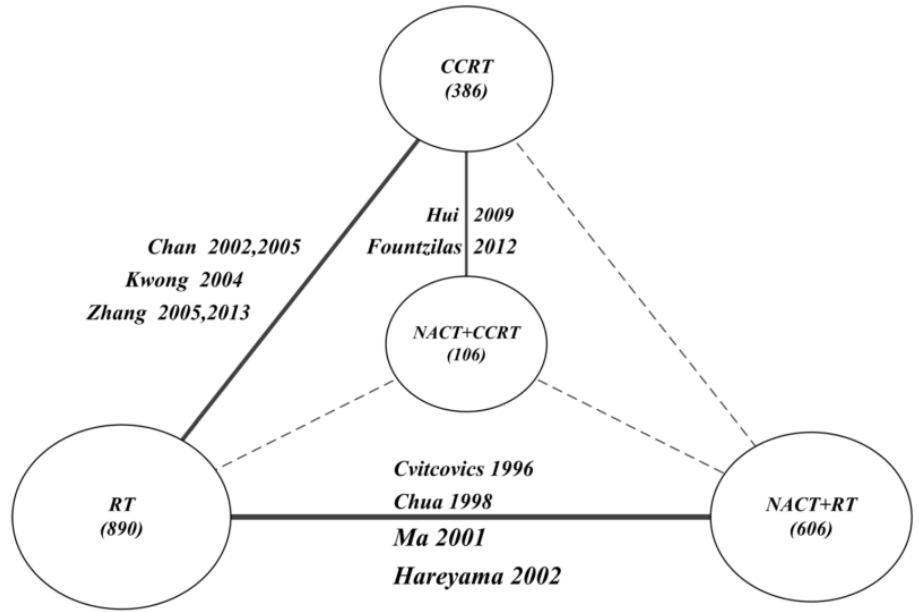

Figure 3. Multiple treatment comparison network. Each treatment area is proportional to the cumulative number of patients (in parentheses). Solid lines between treatments represent direct comparisons; line thickness corresponds to the number of trials (beside the line) comparing the connected treatments. NACT: neoadjuvant chemotherapy; CCRT: concurrent chemoradiotherapy; RT: radiotherapy.

A

\begin{tabular}{l|c|c}
\hline NACT+CCRT & $0.73(0.40-1.23)$ & $0.58(0.29-1.06)$ \\
& $0.70(0.31-1.33)$ & $0.57(0.21-1.22)$ \\
& & $0.79(0.58-1.08)$ \\
& CCRT & $0.81(0.44-1.36)$ \\
& & \\
& & NACT+RT \\
DIC &
\end{tabular}

Fixed-effects model: 6.4

Random-effects model: 8.2

$\mathbf{C}$

\begin{tabular}{|c|cc}
\hline NACT+CCRT & $1.71(0.94-2.84)$ & $2.22(1.02-4.14)$ \\
& $1.76(0.87-3.23)$ & $2.29(0.90-5.05)$ \\
& & $1.30(0.81-1.96)$ \\
& CCRT & $1.33(0.73-2.11)$ \\
& & \\
& & NACT+RT \\
DIC &
\end{tabular}

Fixed-effects model: 3.2

Random-effects model: 5.2

E

\begin{tabular}{l|ccc} 
& & & \\
NACT+CCRT & $0.54(0.27-0.94)$ & $0.56(0.23-1.02)$ & $0.40(0.19-0.75)$ \\
& $0.53(0.24-0.99)$ & $0.57(0.22-1.21)$ & $0.38(0.16-0.76)$ \\
& & $1.05(0.71-1.43)$ & $0.75(0.55-0.97)$ \\
& \multicolumn{1}{c}{ CCRT } & $1.07(0.67-1.67)$ & $0.73(0.45-1.00)$ \\
& & \\
& & \\
& & & $0.72(0.58-0.88)$ \\
NIC & & $0.71(0.54-0.93)$ \\
Fixed-effects model: 4.5 & & RT \\
Random-effects model: 6.0 &
\end{tabular}

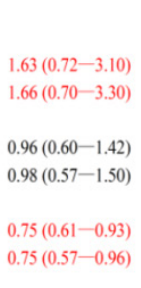

\section{Overall survival}
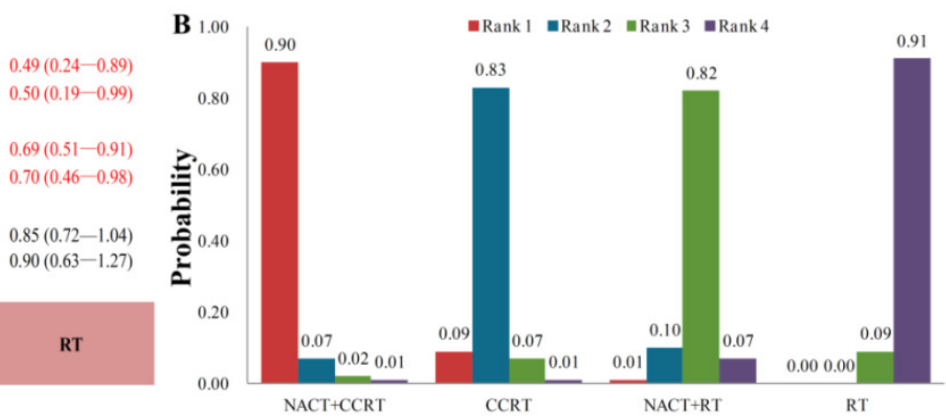

Locoregional recurrence rate

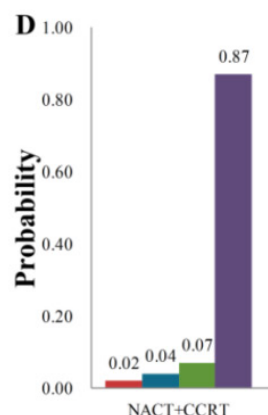

-Rank 1 -Rank 2 -Rank 3 - Rank 4

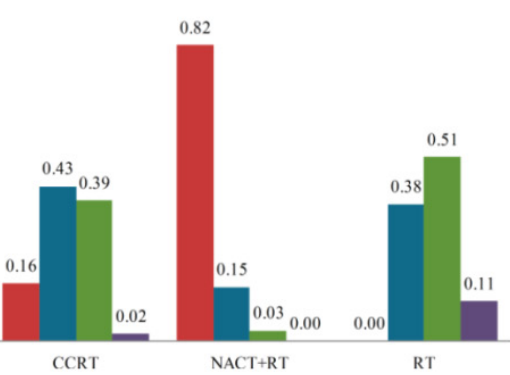

Distant metastasis rate

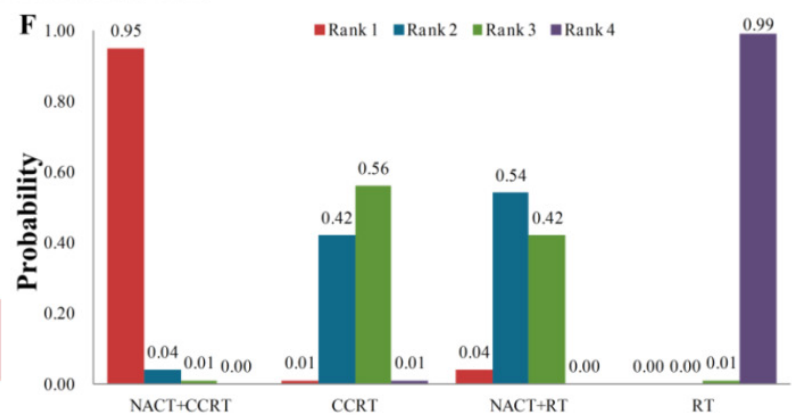

Figure 4. Network meta-analysis results for overall survival (A, B), locoregional recurrence rate (C, D), and distant metastasis rate (E, F). (A, C, E) Upper triangles denote pooled hazard ratios (HRs) for overall survival, and pooled relative risks (RRs) for locoregional recurrence rate and distant metastasis rate; treatments in the rows were compared with those in the columns. In each HR/RR cell, the first and second lines contain the HRs/RRs from the fixed and random effects models, respectively. Numbers in parentheses indicate the corresponding $95 \%$ credible intervals. Red numbers, HRs/RRs with Bayesian $P<0.05$. Lower triangles denote the Bayesian deviance information criterion (DIC) statistics from the fixed and random effects models. (B, D, F) Probabilities of each treatment ranking best, and second and third best based on the fixed effects model. NACT: neoadjuvant chemotherapy; CCRT: concurrent chemoradiotherapy; RT: radiotherapy. 
Table 3. Cumulative incidence rate (\%) of severe acute toxicities in studies evaluating additional NACT included in the network meta-analysis

\begin{tabular}{|c|c|c|c|c|c|c|c|c|}
\hline \multirow{2}{*}{$\begin{array}{l}\text { Severe } \\
\text { acute toxicities } \\
(\geq \text { Grade } 3)\end{array}$} & \multicolumn{2}{|c|}{ NACT+CCRT vs. CCRT } & \multicolumn{4}{|c|}{ NACT+RT vs. RT } & \multirow{2}{*}{$\begin{array}{l}\text { Weighted } \\
\text { incidence }\end{array}$} & \multirow[t]{2}{*}{$P$-value a } \\
\hline & $\begin{array}{l}\text { Hui et } \\
\text { al. [12] } 2009\end{array}$ & $\begin{array}{l}\text { Fountzilas } \\
\text { et al. [13] } 2012\end{array}$ & $\begin{array}{l}\text { Cvitcovics } \\
\text { et al. [7]1996 }\end{array}$ & $\begin{array}{l}\text { Chua et al. } \\
{[8] 1998}\end{array}$ & $\begin{array}{l}\text { Ma et al. } \\
\text { [9] } 2001\end{array}$ & $\begin{array}{l}\text { Hareyama et al. [10] } \\
2002\end{array}$ & & \\
\hline \multicolumn{9}{|l|}{ During NACT } \\
\hline \multicolumn{9}{|l|}{ Hematologic } \\
\hline Anemia & 0 & 2 & NA & 2 & 3 & NA & 2.3 & -- \\
\hline Leukopenia & NA & NA & NA & 2 & 4 & NA & 3.2 & -- \\
\hline Neutropenia & 97 & 9 & 6 & NA & NA & 4 & 17.3 & -- \\
\hline Neutropenic fever & 12 & NA & NA & 3 & NA & NA & 4.5 & -- \\
\hline Thrombocytopenia & 0 & NA & NA & 0 & 1 & 4 & 0.8 & -- \\
\hline \multicolumn{9}{|l|}{ Nonhematologic } \\
\hline Fatigue & 6 & 2 & NA & NA & NA & NA & 3.4 & -- \\
\hline Nausea/Vomiting & 9 & NA & 49 & 25 & 13 & 28 & 25.6 & -- \\
\hline Renal toxicity & NA & NA & 9 & NA & 0 & 0 & 3.2 & -- \\
\hline Hair loss & NA & 55 & NA & 25 & 0 & NA & 17.4 & -- \\
\hline \multicolumn{9}{|l|}{ During CCRT or RT } \\
\hline \multicolumn{9}{|l|}{ Hematologic } \\
\hline Anemia & 9 vs. 19 & 5 vs. 0 & NA & NA & NA & NA & 6.4 vs. $5.1^{b}$ & $0.770^{\mathrm{b}}$ \\
\hline Leukopenia & NA & $26 v s .30$ & NA & NA & NA & NA & 26.0 vs. $30.0^{\mathrm{b}}$ & $0.554^{\mathrm{b}}$ \\
\hline Neutropenia & 26vs.15 & 6 vs. 11 & NA & NA & NA & NA & & $0.852^{b}$ \\
\hline Neutropenic fever & 3 vs. 4 & 0 vs.1 & NA & NA & NA & NA & $13.0^{\text {vs } .12 .1^{b}}$ & $0.993^{b}$ \\
\hline Thrombocytopenia & 9 vs. 4 & 16 vs. 1 & NA & NA & NA & NA & 1.1 vs. $1.8^{\mathrm{b}}$ & $0.003^{b}$ \\
\hline Nonhematologic & & & & & & & 13.5 vs. $1.8^{b}$ & \\
\hline Nausea/Vomiting & 9 vs. 8 & 21vs.19 & NA & NA & NA & NA & 16.8 vs. $16.0^{b}$ & $0.869 \mathrm{~b}$ \\
\hline Skin & NA & 6 vs. 24 & 10 vs. 9 & NA & NA & NA & 6.0 vs. $24.0^{b}$ & $0.005^{b}$ \\
\hline Renal toxicity & $24 \mathrm{vs} .23$ & 0 vs. 1 & NA & NA & NA & NA & 8.4 vs. $7.0^{\mathrm{b}}$ & $0.804^{b}$ \\
\hline Fatigue & 15 vs. 8 & 0 vs. 3 & NA & NA & NA & NA & 5.3 vs. $4.4^{b}$ & $0.745^{b}$ \\
\hline Mucositis & 24 vs. 8 & 53vs.54 & 18 vs. 20 & NA & NA & NA & $27.9 \mathrm{vs} .28 .0^{\mathrm{b}}$ & $0.962 \mathrm{~b}$ \\
\hline
\end{tabular}

Significant beneficial treatment effect of NACT+CCRT over CCRT for DMR was found in our study. However, NACT+CCRT had a tendency to be associated with significantly poor locoregional control as compared with CCRT $(\mathrm{RR}=1.71,95 \% \mathrm{CrI}=$ 0.94-2.84), and no significant improvement in OS was found $(\mathrm{HR}=0.73,95 \% \mathrm{CrI}=0.40-1.23)$. An explanation for these results may be that the two recent trials by Hui et al. [12] and Fountzilas et al. [13] both showed poor locoregional control of NACT+CCRT as compared with CCRT. Thus, an RR $>1$ was found for LRR in our analysis, which means the addition of NACT to CCRT may even has a tendency to worsen the efficacy of locoregional control. Considering that IMRT/3-dimensional conformal radiation therapy (3DCRT) were adopted in these two trials, this seems to be reasonable because IMRT/3DCRT had achieved good locoregional control [32], by which the actual benefit of NACT for LRR may be diluted. Furthermore, the toxic effect of NACT could result in the delay of subsequent CCRT and accelerated proliferation of tumor cells, which may offset any possible benefit on locoregional control and even survival [7]. Therefore, the favorable effect of NACT+CCRT on distant failure control can be diluted by its relatively unfavorable effect on locoregional control, which in all results in the unsignificant difference for overall sur- vival. Still, NACT+CCRT ranked best for OS (90\%). Nontheless, it should be noted that even if the effect size differences among treatments were small and non-significant, a probability of treatment ranking would have been produced without a clear statistical meaning. In fact, NACT+CCRT and CCRT did not differ significantly for OS.

The ESMO recommends that cisplatinum-based NACT could be considered in locally advanced disease, and in no case should it negatively affect the optimal administration of concomitant chemoradiation [27]. According to the results of this network meta-analysis, we suppose that the addition of NACT to CCRT has the potential to maximize the benefit from both approaches, and the change of chemotherapy sequence from adjuvant chemotherapy to NACT followed by CCRT may reduce the toxic effect. It is of great significance for us to optimize the NACT regimens to enhance efficacy and compliance. The use of taxane may be one effective way for regimen improvement, which acts by a different mechanism other than the cisplatin and fluorouracil with an uncomplicated and manageable toxicity [10, 12, 13]. A recent meta-analysis in locally advanced head and neck cancers indicated the superiority of taxane-cisplatin-fluorouracil over cisplatin-fluorouracil as neoadjuvant chemotherapy [33]. Gemcitabine may 
also be a choice [34]. Currently, several phase III trials are undertaking to confirme the efficacies of these regimens for locoregionally advanced NPC (NCT01245959, NCT01872962, CDR0000657121), and the final results are awaiting to be reported.

Our study also point to the importance of identifying a high risk patient group that may benefit most from NACT+CCRT. The natural history and failure patterns are quite different between NPC patients with predominantly advanced local disease (advanced $\mathrm{T}$ classification) but early stage cervical lymph node involvement (early $\mathrm{N}$ classification), and those with advanced lymph node disease (advanced $\mathrm{N}$ classification) but early stage local invasion (early $\mathrm{T}$ calssification). Patients in the former group usually experience local failure while patients in the latter one experience distant failure more often. Considering the favorable effect of NACT+CCRT on distant failure control, it is logical to expect that locoregionally advanced NPC patients predominantly being at high risk of distant metastasis (early $\mathrm{T}$ classification and advanced $\mathrm{N}$ classification) can gain the most benefit from NACT+CCRT. Lots of biomarkers associated with distant metastasis can also be helpful for the identification [35].

The study limitations also should be acknowledged. First, we extracted all information from published data other than individual patient data. Some of the unreported individual patient information may have an impact on our quality control and statistical analysis, which may have resulted in publication and reporting bias. But we endeavored to minimize the risk of bias through searching and reviewing the publications comprehensively, and extracting the data by two investigators independently as well as assessing the quality of RCTs systematically. Good consistency was confirmed. Second, there was only a short-term result of the trial by Hui et al. [12], in which NACT+CCRT was found to be significantly superior to CCRT for OS. The long-term follow-up results of this trial, which may be instructive and affect our analysis of NACT+CCRT efficacy for OS, have not been published yet.

In conclusion, our network meta-analysis showed that despite the relatively poor locoregional control, NACT+CCRT was associated with favorable distant failure control when compared with CCRT alone. Whether NACT+CCRT could improve overall survival should be further explored. Optimizing regimens and identifying patients at high risk of distant metastasis may enhance the efficacy of NACT+CCRT. NACT+CCRT has a bright prospect and further researches designed to confirm its potential therapeutic benefit are awaited.

\section{Abbreviations}

CCRT: concurrent chemoradiotherapy; CI: confidence interval; CrI: credible interval; CT: computed tomography; DIC: deviance information criterion; DMR: distant metastasis rate; ESMO: European Society for Medical Oncology; HR: hazard ratio; IMRT: intensity modulated radiation therapy; LRR: locoregional recurrence rate; MRI: magnetic resonance imaging; PRISMA: Preferred Reporting Items for Systematic Reviews and Meta-Analyses; NACT: neoadjuvant chemotherapy; NCCN: National Comprehensive Cancer Network; NCI: National Cancer Institute; NPC: nasopharyngeal carcinoma; OS: overall survival; RCT: randomized controlled trial; RR: relative risk; RT: radiotherapy; WHO: World Health Organization.

\section{Acknowledgments}

This work was supported by grants from the Health \& Medical Collaborative Innovation Project of Guangzhou City, China (201400000001), the Science and Technology Project of Guangzhou City, China (14570006), the National Science \& Technology Pillar Program during the Twelfth Five-year Plan Period (2014BAI09B10), the Planned Science and Technology Project of Guangdong Province (2013B020400004), the Key Laboratory Construction Project of Guangzhou City, China (121800085), the National Natural Science Foundation of China (81302366) and the Medical Science and Technology Research Foundation of Guangdong Province (B2013148).

\section{Conflict of Interest}

The authors declare no conflict of interest.

\section{References}

1. Wei WI, Sham JS. Nasopharyngeal carcinoma. Lancet. 2005; 365: 2041-54.

2. Wee J. Nasopharyngeal cancer: a promising future. Lancet Oncol. 2012; 13: 116-8.

3. Lai SZ, Li WF, Chen L, Luo W, Chen YY, Liu LZ, et al. How does intensity-modulated radiotherapy versus conventional two-dimensional radiotherapy influence the treatment results in nasopharyngeal carcinoma patients? International journal of radiation oncology, biology, physics. 2011; 80: 661-8.

4. Baujat B, Audry H, Bourhis J, Chan AT, Onat H, Chua DT, et al. Chemotherapy in locally advanced nasopharyngeal carcinoma: an individual patient data meta-analysis of eight randomized trials and 1753 patients. International journal of radiation oncology, biology, physics. 2006; 64: 47-56.

5. Blanchard P, Lee AWM, Leclercq J, Marguet S, Ng WT, Ma J, et al. Meta-analysis of chemotherapy in nasopharyngeal carcinoma (MAC-NPC): An update on 4,798 patients. ASCO Meeting Abstracts. 2014; 32: 6022

6. Chen YP, Wang ZX, Chen L, Liu X, Tang LL, Mao YP, et al. A Bayesian network meta-analysis comparing concurrent chemoradiotherapy followed by adjuvant chemotherapy, concurrent chemoradiotherapy alone and radiotherapy alone in patients with locoregionally advanced nasopharyngeal carcinoma. Ann Oncol. 2014.

7. International Nasopharynx Cancer Study G, Trial VI. Preliminary results of a randomized trial comparing neoadjuvant chemotherapy (cisplatin, epirubicin, bleomycin) plus radiotherapy vs. radiotherapy alone in stage $\operatorname{IV}(>$ or $=\mathrm{N} 2$, M0) undifferentiated nasopharyngeal carcinoma: a positive effect on progression-free survival. International journal of radiation oncology, biology, physics. 1996; 35: 463-9.

8. Chua DT, Sham JS, Choy D, Lorvidhaya V, Sumitsawan Y, Thongprasert S, et al. Preliminary report of the Asian-Oceanian Clinical Oncology Association randomized trial comparing cisplatin and epirubicin followed by radiotherapy versus radiotherapy alone in the treatment of patients with locoregionally 
advanced nasopharyngeal carcinoma. Asian-Oceanian Clinical Oncology Association Nasopharynx Cancer Study Group. Cancer. 1998; 83: 2270-83.

9. Ma J, Mai HQ, Hong MH, Min HQ, Mao ZD, Cui NJ, et al. Results of a prospective randomized trial comparing neoadjuvant chemotherapy plus radiotherapy with radiotherapy alone in patients with locoregionally advanced nasopharyngeal carcinoma. J Clin Oncol. 2001; 19: 1350-7.

10. Hareyama M, Sakata K, Shirato H, Nishioka T, Nishio M, Suzuki K, et al. A prospective, randomized trial comparing neoadjuvant chemotherapy with radiotherapy alone in patients with advanced nasopharyngeal carcinoma. Cancer. 2002; 94: 2217-23.

11. OuYang PY, Xie C, Mao YP, Zhang Y, Liang XX, Su Z, et al. Significant efficacies of neoadjuvant and adjuvant chemotherapy for nasopharyngeal carcinoma by meta-analysis of published literature-based randomized, controlled trials. Ann Oncol. 2013; 24: 2136-46.

12. Hui EP, Ma BB, Leung SF, King AD, Mo F, Kam MK, et al. Randomized phase II trial of concurrent cisplatin-radiotherapy with or without neoadjuvant docetaxel and cisplatin in advanced nasopharyngeal carcinoma. J Clin Oncol. 2009; 27: 242-9.

13. Fountzilas G, Ciuleanu E, Bobos M, Kalogera-Fountzila A, Eleftheraki AG, Karayannopoulou G, et al. Induction chemotherapy followed by concomitant radiotherapy and weekly cisplatin versus the same concomitant chemoradiotherapy in patients with nasopharyngeal carcinoma: a randomized phase II study conducted by the Hellenic Cooperative Oncology Group (HeCOG) with biomarker evaluation. Ann Oncol. 2012; 23: 427-35.

14. Moher D, Liberati A, Tetzlaff J, Altman DG, Group P. Preferred reporting items for systematic reviews and meta-analyses: the PRISMA statement. Bmj. 2009; 339: b2535.

15. Jadad AR, Moore RA, Carroll D, Jenkinson C, Reynolds DJ, Gavaghan DJ, et al. Assessing the quality of reports of randomized clinical trials: is blinding necessary? Control Clin Trials. 1996; 17: 1-12.

16. Parmar MK, Torri V, Stewart L. Extracting summary statistics to perform meta-analyses of the published literature for survival endpoints. Stat Med. 1998; 17: 2815-34.

17. Fryback DG, Stout NK, Rosenberg MA. An elementary introduction to Bayesian computing using WinBUGS. Int J Technol Assess Health Care. 2001; 17: $98-113$.

18. Woods BS, Hawkins N, Scott DA. Network meta-analysis on the log-hazard scale, combining count and hazard ratio statistics accounting for multi-arm trials: a tutorial. BMC medical research methodology. 2010; 10: 54.

19. Wandel S, Juni P, Tendal B, Nuesch E, Villiger PM, Welton NJ, et al. Effects of glucosamine, chondroitin, or placebo in patients with osteoarthritis of hip or knee: network meta-analysis. Bmj. 2010; 341: c4675.

20. Spiegelhalter DJ, Best NG, Carlin BP, Linde AVD. Bayesian measures of model complexity and fit. J R Stat Soc. 2002; 64: 583-639.

21. Brooks SP, Gelman A. General methods for monitoring convergence of iterative simulations. J Comput Graph Stat. 1998; 7: 434-55.

22. Chan AT, Teo PM, Ngan RK, Leung TW, Lau WH, Zee B, et al. Concurrent chemotherapy-radiotherapy compared with radiotherapy alone in locoregionally advanced nasopharyngeal carcinoma: progression-free survival analysis of a phase III randomized trial. J Clin Oncol. 2002; 20: 2038-44.

23. Chan AT, Leung SF, Ngan RK, Teo PM, Lau WH, Kwan WH, et al. Overall survival after concurrent cisplatin-radiotherapy compared with radiotherapy alone in locoregionally advanced nasopharyngeal carcinoma. J Natl Cancer Inst. 2005; 97: 536-9.

24. Kwong DL, Sham JS, Au GK, Chua DT, Kwong PW, Cheng AC, et al. Concurrent and adjuvant chemotherapy for nasopharyngeal carcinoma: a factorial study. J Clin Oncol. 2004; 22: 2643-53.

25. Zhang L, Zhao C, Peng PJ, Lu LX, Huang PY, Han F, et al. Phase III study comparing standard radiotherapy with or without weekly oxaliplatin in treatment of locoregionally advanced nasopharyngeal carcinoma: preliminary results. J Clin Oncol. 2005; 23: 8461-8.

26. Wu X, Huang PY, Peng PI, Lu LX, Han F, Wu SX, et al. Long-term follow-up of a phase III study comparing radiotherapy with or without weekly oxaliplatin for locoregionally advanced nasopharyngeal carcinoma. Ann Oncol. 2013; 24: 2131-6.

27. Chan AT, Gregoire V, Lefebvre JL, Licitra L, Hui EP, Leung SF, et al. Nasopharyngeal cancer: EHNS-ESMO-ESTRO Clinical Practice Guidelines for diagnosis, treatment and follow-up. Ann Oncol. 2012; 23 Suppl 7: vii83-5.

28. Lin JC, Liang WM, Jan JS, Jiang RS, Lin AC. Another way to estimate outcome of advanced nasopharyngeal carcinoma--is concurrent chemoradiotherapy adequate? International journal of radiation oncology, biology, physics. 2004; 60: $156-64$

29. Chua DT, Ma J, Sham JS, Mai HQ, Choy DT, Hong MH, et al. Long-term survival after cisplatin-based induction chemotherapy and radiotherapy for nasopharyngeal carcinoma: a pooled data analysis of two phase III trials. J Clin Oncol. 2005; 23: 1118-24.

30. Chua DT, Sham JS, Choy D, Kwong DL, Au GK, Kwong PW, et al. Patterns of failure after induction chemotherapy and radiotherapy for locoregionally advanced nasopharyngeal carcinoma: the Queen Mary Hospital experience. International journal of radiation oncology, biology, physics. 2001; 49: 1219-28.

31. Teo PM, Chan AT, Lee WY, Leung TW, Johnson PJ. Enhancement of local control in locally advanced node-positive nasopharyngeal carcinoma by adjunctive chemotherapy. International journal of radiation oncology, biology, physics. 1999; 43: 261-71.
32. Lee N, Xia P, Quivey JM, Sultanem $\mathrm{K}$, Poon I, Akazawa $\mathrm{C}$, et al. Intensity-modulated radiotherapy in the treatment of nasopharyngeal carcinoma: an update of the UCSF experience. International journal of radiation oncology, biology, physics. 2002; 53: 12-22.

33. Blanchard P, Bourhis J, Lacas B, Posner MR, Vermorken JB, Hernandez JJ, et al. Taxane-cisplatin-fluorouracil as induction chemotherapy in locally advanced head and neck cancers: an individual patient data meta-analysis of the meta-analysis of chemotherapy in head and neck cancer group. J Clin Oncol. 2013; 31: 2854-60.

34. Leong SS, Wee J, Tay MH, Toh CK, Tan SB, Thng CH, et al. Paclitaxel, carboplatin, and gemcitabine in metastatic nasopharyngeal carcinoma: a Phase II trial using a triplet combination. Cancer. 2005; 103: 569-75.

35. Liu N, Chen NY, Cui RX, Li WF, Li Y, Wei RR, et al. Prognostic value of a microRNA signature in nasopharyngeal carcinoma: a microRNA expression analysis. Lancet Oncol. 2012; 13: 633-41. 